\title{
ESTUDO SOBRE A APLICAÇÃO DOS CONCEITOS DE HISTÓRIA DA CINÉTICA QUÍMICA NOS LIVROS DIDÁTICOS DO ENSINO MÉDIO
}

\author{
José Carlos Gonçalves Coutinho' \\ Vitor dos Santos Ferreira ${ }^{2}$ \\ Terezinha Iolanda Ayres Pereira ${ }^{3}$
}

Resumo: O artigo busca fazer um paralelo sobre a contribuição da história da cinética química para o ensino dos estudantes do ensino médio e a abordagem histórica apresentada pelos livros didáticos sobre a cinética química. Na literatura são citados vários benefícios que a inclusão de história da ciência pode trazer para o aprendizado. A ideia de que as reações químicas ocorrem em diferentes velocidades já estava presente em estudos que foram realizados em diferentes épocas. Muitos dos experimentos feitos pelos pesquisadores que formularam os conceitos primordiais da cinética química podem ser facilmente reproduzidos hoje em dia, principalmente ao trabalhar cinética química no ensino médio. No Brasil, o uso do contexto histórico aparece explícito em documentos oficiais, como os Parâmetros Curriculares Nacionais para o Ensino Médio (PCNs) e as Novas Diretrizes Curriculares para os cursos de graduação, porém os livros didáticos que foram analisados não trazem o uso do contexto histórico como uma de suas ferramentas na explicação dos conceitos da cinética química.

Palavras-chave: História da química; Cinética química; Livros Didáticos.

\footnotetext{
1 Universidade do Estado de Minas Gerais, Brasil. E-mail: jccoutinho31@gmail.com.

2 Universidade do Estado de Minas Gerais, Brasil. E-mail: vitor.ferreira@uemguba.edu.br.

3 Universidade do Estado de Minas Gerais, Brasil. E-mail: tiayres@gmail.com.
} 